Bond University

Research Repository

\title{
Corticosteroids for the common cold
}

Hayward, Gail; Thompson, Matthew J.; Perera, Rafael; Del Mar, Chris B.; Glasziou, Paul P.; Heneghan, Carl J.

Published in:

Cochrane Database of Systematic Reviews

DOI:

10.1002/14651858.CD008116.pub3

Licence:

Other

Link to output in Bond University research repository.

Recommended citation $(A P A)$ :

Hayward, G., Thompson, M. J., Perera, R., Del Mar, C. B., Glasziou, P. P., \& Heneghan, C. J. (2015).

Corticosteroids for the common cold. Cochrane Database of Systematic Reviews, 2015(3), [CD008116]. https://doi.org/10.1002/14651858.CD008116.pub3

\section{General rights}

Copyright and moral rights for the publications made accessible in the public portal are retained by the authors and/or other copyright owners and it is a condition of accessing publications that users recognise and abide by the legal requirements associated with these rights.

For more information, or if you believe that this document breaches copyright, please contact the Bond University research repository coordinator. 


\section{(F) Cochrane Library}

Cochrane Database of Systematic Reviews

\section{Corticosteroids for the common cold (Review)}

Hayward G, Thompson MJ, Perera R, Del Mar CB, Glasziou PP, Heneghan CJ

Hayward G, Thompson MJ, Perera R, Del Mar CB, Glasziou PP, Heneghan CJ.

Corticosteroids for the common cold.

Cochrane Database of Systematic Reviews 2015, Issue 10. Art. No.: CD008116.

DOI: 10.1002/14651858.CD008116.pub3.

www.cochranelibrary.com

Corticosteroids for the common cold (Review) 


\section{TABLE OF CONTENTS}

HEADER

ABSTRACT

PLAIN LANGUAGE SUMMARY

BACKGROUND

OBJECTIVES

METHODS

RESULTS

Figure 1.

Figure 2 .

Figure 3.

DISCUSSION

AUTHORS' CONCLUSIONS

ACKNOWLEDGEMENTS

REFERENCES

CHARACTERISTICS OF STUDIES

DATA AND ANALYSES

Analysis 1.1. Comparison 1 Rhinovirus infection, Outcome 1 Number of patients with rhinovirus-positive nasopharyngeal aspirates at day 7 of treatment. . . . . . . . . . . . . . . . . . . . . . . . . . . . . . . . . . . . . . . . . . 20

APPENDICES . . . . . . . . . . . . . . . . . . . . . . . . . . . . . . . . . . . . . 20

FEEDBACK . . . . . . . . . . . . . . . . . . . . . . . . . . . . . . . . . . . . . . . . . 24

WHAT'S NEW . . . . . . . . . . . . . . . . . . . . . . . . . . . . . . . . . . . . . . . . 25

HISTORY . . . . . . . . . . . . . . . . . . . . . . . . . . . . . . . . . . . 25

CONTRIBUTIONS OF AUTHORS . . . . . . . . . . . . . . . . . . . . . . . . . . . . . . . . . . . . . . . $\quad 25$

DECLARATIONS OF INTEREST . . . . . . . . . . . . . . . . . . . . . . . . . . . . . . . . . . 25

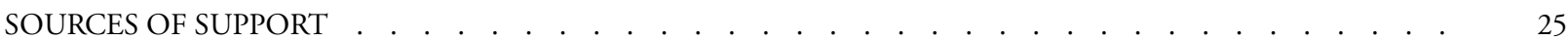

DIFFERENCES BETWEEN PROTOCOL AND REVIEW . . . . . . . . . . . . . . . . . . . . . . . . . 26

INDEX TERMS . . . . . . . . . . . . . . . . . . . . . . . . . . . . . . . . . . . . . 26 


\title{
[Intervention Review]
}

\section{Corticosteroids for the common cold}

\author{
Gail Hayward ${ }^{1}$, Matthew J Thompson ${ }^{2}$, Rafael Perera ${ }^{1}$, Chris B Del Mar ${ }^{3}$, Paul P Glasziou ${ }^{3}$, Carl J Heneghan ${ }^{1}$ \\ ${ }^{1}$ Nuffield Department of Primary Care Health Sciences, University of Oxford, Oxford, UK. ${ }^{2}$ Department of Family Medicine, \\ University of Washington, Seattle, WA, USA. ${ }^{3}$ Centre for Research in Evidence-Based Practice (CREBP), Bond University, Gold Coast, \\ Australia \\ Contact address: Gail Hayward, Nuffield Department of Primary Care Health Sciences, University of Oxford, New Radcliffe House, \\ Radcliffe Observatory Quarter, Oxford, Oxfordshire, OX2 6GG, UK. gail.hayward@phc.ox.ac.uk, ghayward1@googlemail.com.
}

Editorial group: Cochrane Acute Respiratory Infections Group.

Publication status and date: Edited (no change to conclusions), comment added to review, published in Issue 3, 2016.

Citation: Hayward G, Thompson MJ, Perera R, Del Mar CB, Glasziou PP, Heneghan CJ. Corticosteroids for the common cold. Cochrane Database of Systematic Reviews 2015, Issue 10. Art. No.: CD008116. DOI: 10.1002/14651858.CD008116.pub3.

Copyright (C) 2016 The Cochrane Collaboration. Published by John Wiley \& Sons, Ltd.

\begin{abstract}
A B S T R A C T
Background

The common cold is a frequent illness, which, although benign and self limiting, results in many consultations to primary care and considerable loss of school or work days. Current symptomatic treatments have limited benefit. Corticosteroids are an effective treatment in other upper respiratory tract infections and their anti-inflammatory effects may also be beneficial in the common cold. This updated review has included one additional study.
\end{abstract}

\section{Objectives}

To compare corticosteroids versus usual care for the common cold on measures of symptom resolution and improvement in children and adults.

\section{Search methods}

We searched Cochrane Central Register of Controlled Trials (CENTRAL 2015, Issue 4), which includes the Acute Respiratory Infections (ARI) Group's Specialised Register, the Database of Reviews of Effects (DARE) (2015, Issue 2), NHS Health Economics Database (2015, Issue 2), MEDLINE (1948 to May week 3, 2015) and EMBASE (January 2010 to May 2015).

\section{Selection criteria}

Randomised, double-blind, controlled trials comparing corticosteroids to placebo or to standard clinical management.

\section{Data collection and analysis}

Two review authors independently extracted data and assessed trial quality. We were unable to perform meta-analysis and instead present a narrative description of the available evidence.

\section{Main results}

We included three trials (353 participants). Two trials compared intranasal corticosteroids to placebo and one trial compared intranasal corticosteroids to usual care; no trials studied oral corticosteroids. In the two placebo-controlled trials, no benefit of intranasal corticosteroids was demonstrated for duration or severity of symptoms. The risk of bias overall was low or unclear in these two trials. In a trial of 54 participants, the mean number of symptomatic days was 10.3 in the placebo group, compared to 10.7 in those using intranasal corticosteroids (P value $=0.72$ ). A second trial of 199 participants reported no significant differences in the duration of symptoms. The single-blind trial in children aged two to 14 years, who were also receiving oral antibiotics, had inadequate reporting of outcome

Corticosteroids for the common cold (Review)

Copyright () 2016 The Cochrane Collaboration. Published by John Wiley \& Sons, Ltd. 
measures regarding symptom resolution. The overall risk of bias was high for this trial. Mean symptom severity scores were significantly lower in the group receiving intranasal steroids in addition to oral amoxicillin. One placebo-controlled trial reported the presence of rhinovirus in nasal aspirates and found no differences. Only one of the three trials reported on adverse events; no differences were found. Two trials reported secondary bacterial infections (one case of sinusitis, one case of acute otitis media; both in the corticosteroid groups). A lack of comparable outcome measures meant that we were unable to combine the data.

\section{Authors' conclusions}

Current evidence does not support the use of intranasal corticosteroids for symptomatic relief from the common cold. However, there were only three trials, one of which was very poor quality, and there was limited statistical power overall. Further large, randomised, double-blind, placebo-controlled trials in adults and children are required to answer this question.

\section{PLAIN LANGUAGESUMMARY}

\section{Steroids for the common cold}

\section{Review question}

We reviewed the evidence for using steroid medications to improve symptoms in patients who have a common cold.

\section{Background}

Common colds are experienced by over half a billion patients annually in the USA alone and result in significant loss of productivity. Although there are a number of medications used to help improve the symptoms of the common cold, none have good evidence of benefit. Steroids (corticosteroids) have been shown to help relieve symptoms in other types of upper respiratory tract infections by reducing the inflammation of the lining of the nose and throat, which means they might also improve the symptoms of the common cold.

\section{Study characteristics}

Our evidence is current to May 2015. We found three trials in total. Two trials recruited adults from the general population or from among hospital staff in Finland. These trials (total 253 adults) compared intranasal steroid sprays, which allow steroids to be puffed into the nostrils, to sprays containing placebo only. We found a third trial, which recruited 100 children referred to outpatient clinics in an Iranian paediatric hospital. This trial compared intranasal steroid spray to no spray and gave oral antibiotics to all participants.

\section{Key results and quality of the evidence}

Neither of the two trials comparing steroid spray to placebo spray in adults showed a benefit of steroids across a range of different measures. The trial comparing steroid spray to no spray in children did find some evidence of benefit but we rated the quality of the evidence from this trial as very poor and the results were unclear. We could not combine the results of the trials to assess this question further. There were no reports of adverse events.

\section{Conclusion}

The available evidence suggests that we should not use intranasal steroids for the common cold. However, as we found only three small trials, we cannot be sure that there is no effect without performing larger, well-designed trials.

\section{Description of the condition} tract viral infections that are benign and self limiting. Over 500 
million patients develop colds in a year in the United States ( Fendrick 2003), resulting in 22 million school days lost (Adams 1999), and an annual lost productivity of almost USD 25 billion (Bramley 2002).

The typical symptoms of a cold include nasal obstruction, rhinorrhoea, sneezing, sore throat and, on occasion, mild fever, headache and myalgia. The most common causative agent is the rhinovirus (Makela 1998), although several different viral families have been implicated and bacterial infection can give rise to the same symptoms (Kaiser 1996). Rhinoviral infection begins with deposition of virus on the nasal epithelium via airborne droplets or by hand from fomites (any inanimate object, e.g. kitchen sink, that can carry disease-causing organisms). The inflammatory response of nasal mucosa to the viral infection involves vasodilation and increased vascular permeability, leading to the symptoms of sneezing, nasal congestion and rhinorrhoea.

\section{Description of the intervention}

Management options for common colds currently focus on symptom alleviation and include decongestants, where evidence has not recently been assessed, and antihistamines, for which there is no evidence of benefit (Wiest 2011). Whilst both of these therapies target the effects of the inflammatory response of the nasal mucosa to the virus, this inflammatory response could also be modulated by the use of corticosteroids, which inhibit the generation of proinflammatory cytokines in nasal epithelium (Mygind 2001).

\section{How the intervention might work}

Corticosteroids have been demonstrated to increase the likelihood of resolution or improvement of symptoms in acute sinusitis ( Zalmanovici 2013), as well as in viral croup (Russell 2011), and sore throats (Hayward 2009). Their anti-inflammatory actions on the nasal mucosa may also reduce the symptoms and duration of the common cold.

\section{Why it is important to do this review}

The common cold results in significant morbidity and loss of productivity. Current treatment options have limited evidence of benefit. Corticosteroids may offer more effective symptom relief, given their actions in other infections of the upper respiratory tract, and it is important to examine the evidence for this. No previous systematic reviews have addressed this question.

\section{O B JEC T IVES}

To compare corticosteroids versus usual care for the common cold on measures of symptom resolution and improvement in children and adults.

\section{MET HOD S}

\section{Criteria for considering studies for this review}

\section{Types of studies}

Randomised controlled trials (RCTs) comparing corticosteroids to placebo or to standard clinical management (for example, conservative measures such as pain relief) for the common cold.

\section{Types of participants}

Children and adults with the common cold, defined by clinical diagnosis. We excluded trials where a definitive diagnosis of another upper respiratory condition was present (for example, influenza or sinusitis). We also excluded trials where the common cold was experimentally induced if the intervention was initiated before the cold was induced. We did not impose any age limits.

\section{Types of interventions}

Oral or inhaled corticosteroids versus standard clinical care or placebo in the control group. We included trials reporting combined interventions if they allowed a direct comparison between corticosteroids and usual care for the common cold and were unconfounded. By unconfounded, we mean studies where the two groups were not treated differently, except for the provision of steroids to one group. Confounding can occur by the use of a different medication regime (for example, analgesics) for one of the two groups. We excluded them if the two groups were treated unequally apart from the corticosteroids.

\section{Types of outcome measures}

\section{Primary outcomes}

1. Proportion of participants with resolution or improvement of symptoms (individual and global) within one month.

2. Time lapse before resolution of symptoms. 


\section{Secondary outcomes}

1. Adverse events necessitating discontinuation of treatment.

2. Relapse rates.

3. Microbiological consequences, for example, length of shedding of virus from nasopharyngeal secretions, bacterial culture from secretions.

4. Treatment for secondary infections.

5. Quality of life measures and economic costs.

\section{Search methods for identification of studies}

\section{Electronic searches}

For this 2015 update we searched the Cochrane Central Register of Controlled Trials (CENTRAL 2015, Issue 4), which includes the Acute Respiratory Infections (ARI) Group's Specialised Register, MEDLINE (May 2012 to May week 3, 2015) and EMBASE (May 2012 to May 2015). We also searched the Database of Reviews of Effects (DARE) (2015, Issue 2 of 4) and the NHS Health Economics Database (NHS EED) (2015, Issue 2 of 4) from The Cochrane Library.

Previously we searched CENTRAL (2012, Issue 5), the Database of Reviews of Effects (DARE) and the NHS Health Economics Database (searched 22 May 2012), MEDLINE (1948 to May week 2, 2012) and EMBASE (January 2010 to May 2012). We combined the MEDLINE search with the Cochrane Highly Sensitive Search Strategy for identifying randomised trials in MEDLINE: sensitivity- and precision-maximising version, Ovid format (Lefebvre 2011). See Appendix 1 for the MEDLINE and CENTRAL search strategy and Appendix 2 for the EMBASE search strategy.

\section{Searching other resources}

We searched the World Health Organization (WHO) International Clinical Trials Registry Platform (ICTRP) and ClinicalTrials.gov trials registries (latest search 19 May 2014). We searched the reference lists of all studies identified as relevant to increase the yield of relevant study references.

\section{Data collection and analysis}

\section{Selection of studies}

Two review authors (GH, CDM) independently reviewed the titles and abstracts of the electronic search results to select relevant articles. One review author $(\mathrm{GH})$ obtained the full text of these articles. Two review authors (GH, CDM) independently reviewed full-text articles for their inclusion in the review. A third review author $(\mathrm{CH})$ resolved any disagreements by discussion. The review authors were not blinded to the journal of origin, the authors, the institutions or the magnitude of results.

\section{Data extraction and management}

Two review authors (GH, MT, CDM) independently extracted data from included trials, entering data into an extraction template and checking agreement. A third review author $(\mathrm{CH})$ assisted with resolving any disagreements. A statistician (RP) independently reviewed all data extracted from original publications to verify the quality of methods and analysis used. We wrote to the trial authors for clarification of data where information was lacking.

\section{Assessment of risk of bias in included studies}

Two review authors (GH, MT) independently assessed the methodological quality of the included studies, with disagreements documented and resolved by discussion with a third review author $(\mathrm{CH})$. The specific aspects of methodological quality assessed included random sequence generation (selection bias), allocation concealment (selection bias), blinding (performance bias and detection bias), incomplete outcome data (attrition bias), selective reporting (reporting bias), treatment adherence, percentage participation and comparability of groups on baseline characteristics. We used the Cochrane 'Risk of bias' tool to perform the assessment (Higgins 2011).

\section{Measures of treatment effect}

Symptom severity was reported as a mean symptom score in two trials (Qvarnberg 2001; Rahmati 2013). In neither trial was it clear how this was calculated. Duration of symptoms was reported as mean duration of symptoms in days in two trials. We were unable to combine data from individual trials. The number of patients who were rhinovirus-positive at day seven is reported as a risk ratio (Puhakka 1998).

\section{Unit of analysis issues}

We did not encounter unit of analysis issues.

\section{Dealing with missing data}

Completion rates were very high for all of our included trials and so strategies for dealing with missing data were not required.

\section{Assessment of heterogeneity}

We did not assess heterogeneity. 


\section{Assessment of reporting biases}

The small number of studies meant that the use of funnel plots was inappropriate. We attempted to contact trial authors to ask for unpublished results.

\section{Data synthesis}

As our data were not amenable to meta-analysis, we addressed our primary outcomes using a narrative description of the available evidence.

\section{Subgroup analysis and investigation of heterogeneity}

We were unable to perform any subgroup analyses.

\section{Sensitivity analysis}

We were unable to perform sensitivity analysis.

\section{RE S U L T S}

\section{Description of studies}

See Characteristics of included studies and Characteristics of excluded studies tables.

\section{Results of the search}

The initial search of the electronic databases retrieved 2947 records with duplicates removed. MEDLINE yielded 1492 records, CENTRAL 1577 and EMBASE 1211. We also searched HEED and DARE and these yielded 18 and 13 records, respectively. Of these records we identified 10 studies that were potentially eligible based on title and abstract. We obtained full-text copies of all 10 articles. From these 10 we included two studies and excluded eight. In the updated search on 19 May 2015, MEDLINE yielded 166 records, EMBASE 1084, CENTRAL 504, NHS EED 10, HEED 0 and DARE 13 records. Once duplicates were removed the total number of new records was 1216 of which we identified four as potentially eligible based on title and abstract. We obtained fulltext copies and included one additional study (see Figure 1 for the PRISMA flow chart). 
Figure I. PRISMA flow chart.

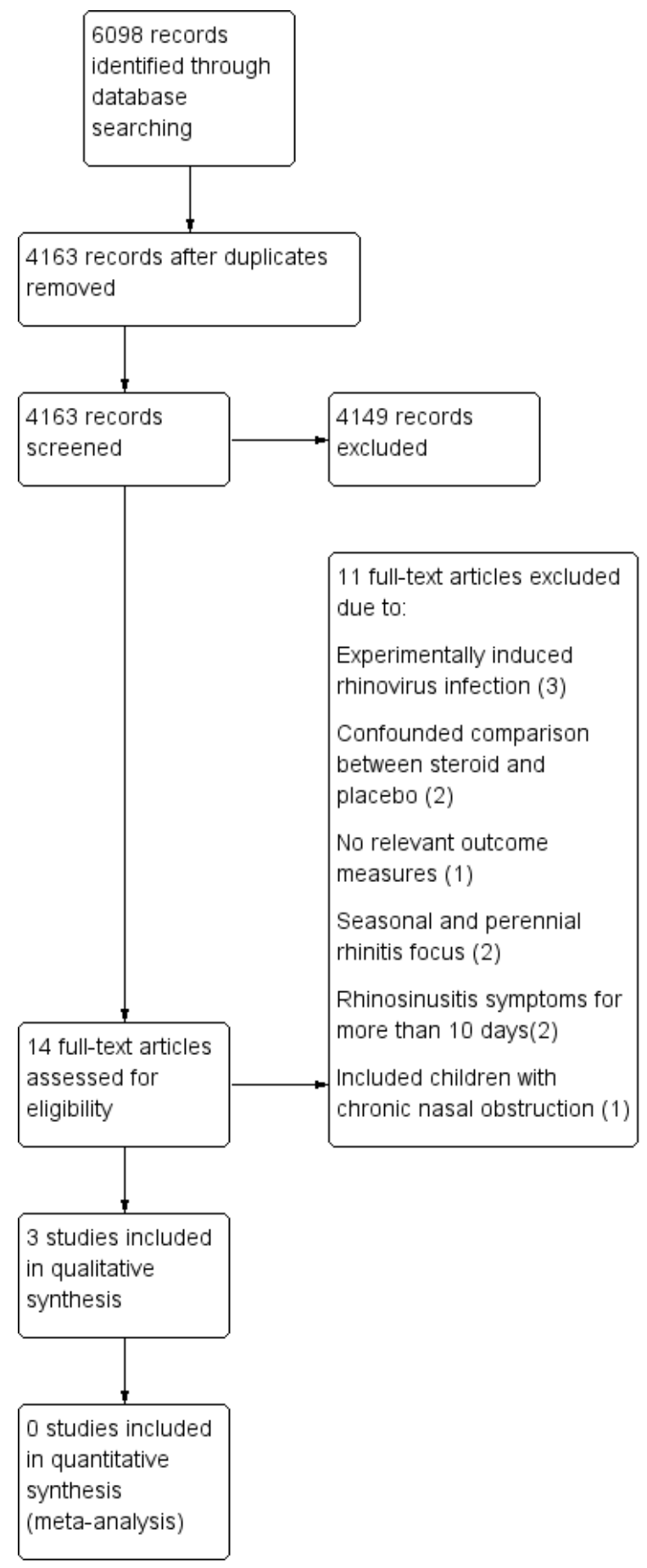




\section{Included studies}

Two of our included studies involved 199 and 54 adult participants respectively, suffering from naturally developed colds (Puhakka 1998; Qvarnberg 2001). Both studies were performed in Finland and recruited from the general population (Puhakka 1998), or hospital staff (Qvarnberg 2001), and the majority were female (190/ 254). Participants received intranasal fluticasone propionate 200 $\mu \mathrm{g}$ four times daily (Puhakka 1998), or beclomethasone dipropionate $400 \mu \mathrm{g}$ once daily (Qvarnberg 2001), for six or 14 days, respectively. The third included study involved 100 children aged two to 14 years attending the paediatric hospital in Bandar Abbas, Iran (Rahmati 2013). Participants received either amoxicillin 80 to $100 \mathrm{mg} / \mathrm{kg}$ alone for 14 days or amoxicillin and fluticasone nasal spray, one puff twice a day, for 14 days. This study aimed to recruit children with acute sinusitis. However, the eligibility criteria included children with symptoms of common cold for less than 10 days with purulent nasal discharge and three days of fever over 39 degrees celsius; criteria compatible with a diagnosis of common cold.

\section{Excluded studies}

We excluded 11 studies. Three studies involved experimentally induced rhinovirus infection and, in each case, the steroid intervention was started before inoculation of rhinovirus (Farr 1990; Gustafson 1996; Proud 1994). Two studies did not offer an unconfounded comparison between steroid and placebo, as their nasal sprays contained antibiotics or mucolytic/vasoconstrictor drugs, which were not also given to the placebo group (Peynegre 2005; Reinert 1991). One study used the same trial population as Puhakka et al to examine salivary constituents and reported no relevant outcome measures (Lenander-Lumikari 1999). One study was a review focusing on seasonal and perennial rhinitis (Mygind 1977), and another excluded infection from its definition of nonallergic rhinitis (Baccioglu Kavut 2013). Two studies assessed a population who presented with rhinosinusitis symptoms for more than 10 days, which we judged to be beyond the natural history of duration of the common cold (Keith 2012; Tugrul 2014), and the final study included children with chronic nasal obstruction (Bellodi 2006).

\section{Risk of bias in included studies}

Two of the studies were double-blind trials comparing intranasal corticosteroid to placebo (Puhakka 1998; Qvarnberg 2001). The method of randomisation was not clearly reported in either study. We were unsuccessful in our attempt to elicit more information to support our assessment of risk of bias directly from the trial authors.

The third study was a single-blind trial comparing intranasal corticosteroid and oral amoxicillin to amoxicillin alone (Rahmati 2013). We elicited further information directly from the authors and found that this study had a high risk of performance, selection and reporting bias.

The overall risk of bias is presented graphically in Figure 2 and summarised in Figure 3. See Characteristics of included studies for further details of our risk of bias assessment.

Figure 2. 'Risk of bias' graph: review authors' judgements about each risk of bias item presented as percentages across all included studies.

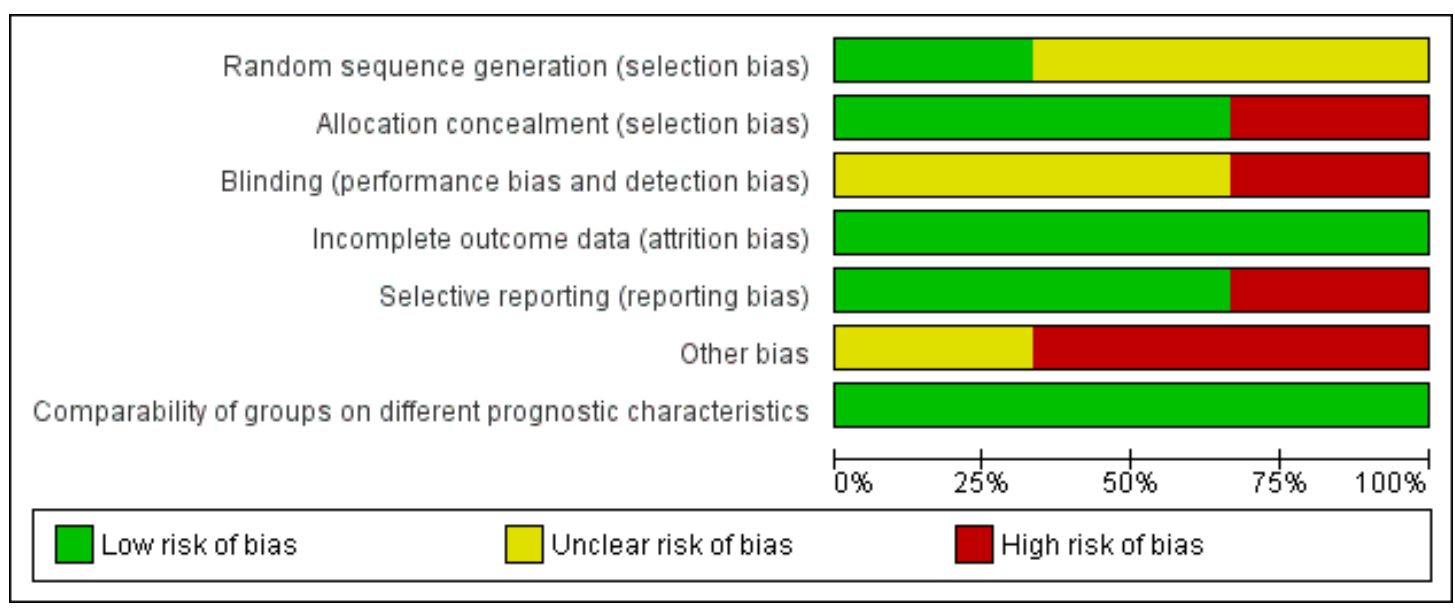

Corticosteroids for the common cold (Review) 
Figure 3. 'Risk of bias' summary: review authors' judgements about each risk of bias item for each included study.

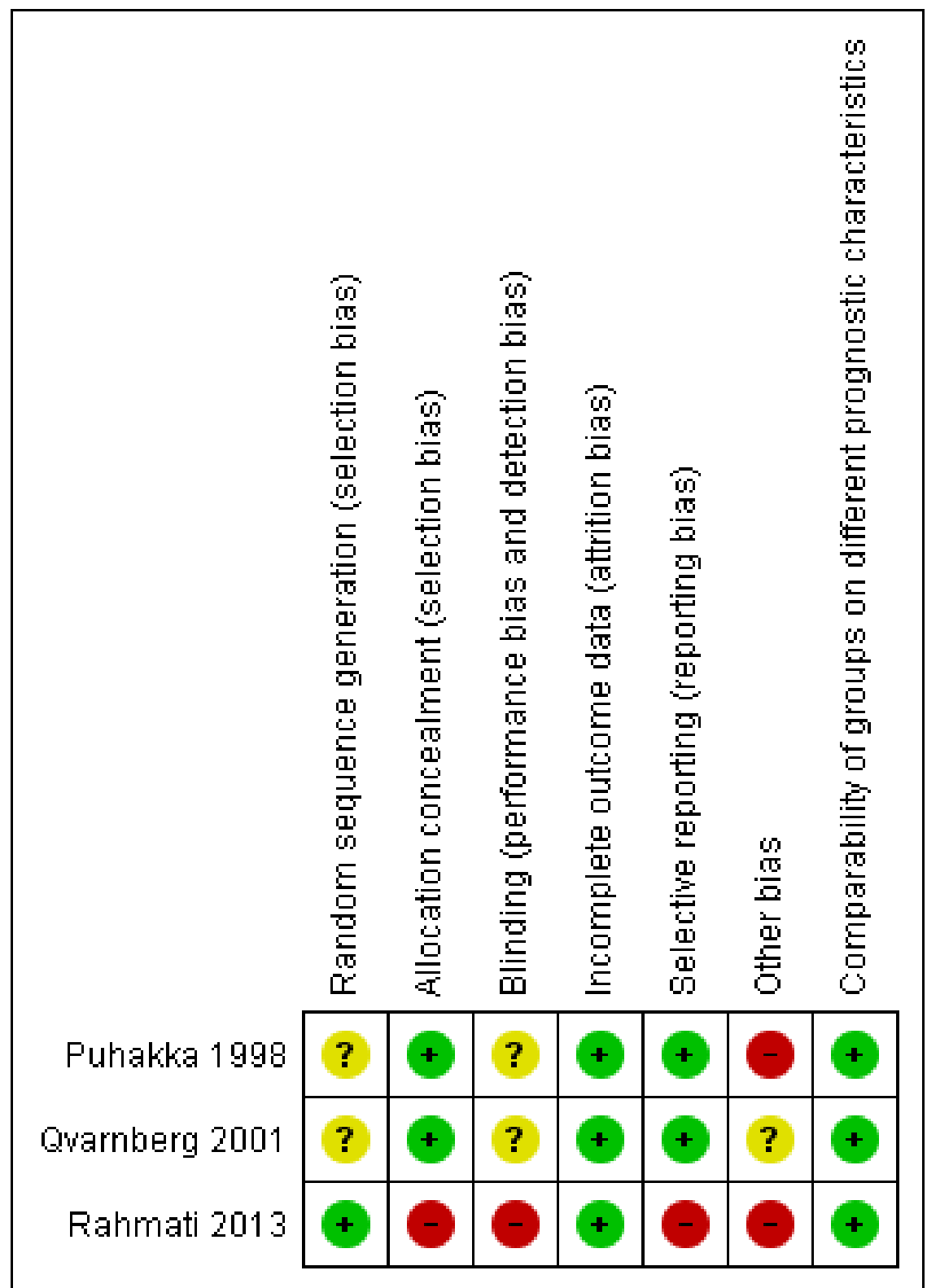




\section{Allocation}

Two studies used placebo intranasal sprays with identical constituents to the intervention spray apart from the active corticosteroid (Puhakka 1998; Qvarnberg 2001). Qvarnberg 2001 used the 'Easyhaler' multidose powder inhaler designed for nasal application for both placebo and steroid. Puhakka 1998 did not directly describe the medication packaging used, although they do report that they received both placebo and corticosteroid sprays from the same pharmaceutical company.

Rahmati 2013 did not use a placebo comparison and therefore had no allocation concealment.

\section{Blinding}

Two studies were described as double-blind (Puhakka 1998; Qvarnberg 2001). No further details regarding this were reported, although Qvarnberg 2001 reported that the randomisation code was only broken after data entry was complete. Rahmati 2013 stated that outcome assessors were blinded, yet a number of outcome measures required patient self report and patients were not blinded as no placebo was used.

\section{Incomplete outcome data}

Completion rates were high in all studies with only 3/353 participants failing to complete; two participants received placebo and one corticosteroid.

\section{Selective reporting}

In two studies, reporting of data was incomplete. Puhakka 1998 stated that data on usage of the trial medications were collected but they did not report these data; if participants in the steroid group had poor compliance with the trial this could reduce the likelihood of any positive effect. Rahmati 2013 displayed inadequate reporting of outcome measures in terms of both the time points of the assessment and the way in which the measures were assessed and calculated.

\section{Other potential sources of bias}

Puhakka 1998 reported that the placebo group as a whole consumed a greater quantity of paracetamol tablets than the steroid group (170 tablets compared to 141). This difference could influence the reporting of symptoms. The Puhakka 1998 trial was supported by GlaxoWellcome Ltd and one trial author was employed by GlaxoWellcome Ltd. This company also manufactured the steroid nasal spray used in the trial. No declarations of conflict of interest were made by the trial authors. The study drug for Qvarnberg 2001 was provided by Orion Pharma, and one of the trial authors worked for the company. No declarations of conflict of interest were made by the trial authors.

Rahmati 2013 stated that if no improvement was seen in fever, nasal congestion or cough, or if exacerbation of disease was evident, patients were reassessed and the antibiotics were changed if necessary. Following direct communication with the authors they stated that "As a whole, patients were assessed again and the antibiotics were changed if necessary at any time. In fact, most of the patients had received a different treatment, if they did not respond to the first line antibiotic therapy after 3 days of the initial treatment." The type and duration of antibiotics once changed is not reported and may have introduced performance bias.

\section{Effects of interventions}

The data extracted from the studies did not provide comparable outcome measures and we were unable to obtain further comparable data directly from the trial authors. Therefore, we have described the results of each trial according to our stated outcome measures.

\section{Primary outcomes}

\section{Proportion of participants with resolution or improvement of symptoms (individual and global) within one month}

Neither Puhakka 1998 nor Qvarnberg 2001 reported this outcome at any time point.

The outcomes of complete and relative resolution were reported as assessed by Rahmati 2013. However, despite direct communication with the authors, we were unable to establish the time point at which these outcomes were assessed or the criteria upon which they were based and therefore we do not feel the evidence is of sufficient quality to be included.

Rahmati 2013 reported a mean 'severity of symptoms' score. It was unclear how this was calculated in relation to the individual symptom scores they report. They state that the score refers to the end of treatment - i.e. 14 days. They found that the score in those children receiving intranasal corticosteroid and amoxicillin reduced from $22.46 \pm 2.61$ to $11.68 \pm 2.66$. In those children just receiving amoxicillin the mean score reduced from $23.5 \pm 3.19$ to $14.84 \pm 2.92$. The final scores were significantly lower in the group receiving intranasal steroids. Qvarnberg 2001 reported that the sum of symptom severity scores over two weeks was similar in the two groups: 57.3 (maximum score 392) in the steroid group versus 51.6 in the placebo group $(\mathrm{P}$ value $=0.48)$. No clinically or statistically significant differences were shown in the summed 
severity (over two weeks follow-up) of the seven individual symptom measures.

Rahmati 2013 also reported the percentage of patients scoring zero to five for individual symptoms (zero for not affected, one for very little problem, two for mild problem, three for moderately bad, four for bad and five for severe). We were unable to clarify the time point at which these scores were assessed. The paper includes a table, which suggests that scores are significantly lower for congestion, anterior discharge, posterior discharge, fullness, headache, cough and malodour, but that scores on exhaustion, fever and toothache were not significantly different. It is unclear how this statistical significance was calculated.

\section{Time lapse before resolution of symptoms}

Puhakka 1998 reported that the duration of the common cold symptoms of rhinorrhoea, nasal congestion and cough was equal in both groups (illustrated in figures in the original article). Mean duration of throat soreness was greater in the corticosteroid group than the placebo group: 5.3 days versus 3.7 days (P value $<0.001$ ). Qvarnberg 2001 reported the mean number of symptomatic days as 10.3 in the placebo group, compared to 10.7 in the corticosteroid group $(\mathrm{P}$ value $=0.72)$. Median time to recovery was 12 days in the steroid group and 11 days in the placebo group (log rank test $P$ value $=0.81$.

Rahmati 2013 did not report this outcome.

\section{Secondary outcomes}

\section{Adverse events necessitating discontinuation of treatment}

Only one study reported adverse events (Puhakka 1998). There were no adverse events necessitating discontinuation of treatment in either group.

\section{Relapse rates}

Puhakka 1998 reported that no participants had symptoms requiring additional follow-up from 21 days after the start of the trial, suggesting a relapse rate of zero. Relapse rates were not assessed by Qvarnberg 2001 or Rahmati 2013.

\section{Microbiological consequences}

Puhakka 1998 was the only trial to assess the presence of rhinovirus by culture and polymerase chain reaction (PCR) of nasopharyngeal aspirates taken on day one and day seven (i.e. at the end of the course of treatment). There were no differences in the percentage of rhinovirus-positive participants at baseline. When assessed by viral culture alone, there were significantly more rhinovirus-positive participants at day seven in the corticosteroid group compared to the placebo group $(36 \%$ versus $14 \%$, P value $<0.001$ ) (Analysis
1.1). However, when the total number of positive samples from day seven detected by PCR and culture were combined there were no significant differences between corticosteroid and placebo groups. Viral culture may offer a more accurate representation of presence of viable virus.

In an intention-to-treat-infected (ITTI) population analysis of only those participants who were rhinovirus-positive on day one, Puhakka 1998 reported no differences in the overall frequency of symptoms between steroid and placebo groups. The mean duration of cough was shorter ( 8.0 versus 10.8 days, $\mathrm{P}$ value $<0.05)$ and the severity of cough was lower on days three, four, seven, eight and nine in the corticosteroid group. Nasal congestion was less severe in the placebo group on days two and five.

No significant differences were seen between treatment groups in the number of positive bacterial cultures from nasopharyngeal aspirates. The effect on viral shedding was not assessed by any of our included studies.

\section{Treatment for secondary infections}

Puhakka 1998 reported that one out of 100 participants receiving corticosteroids and 0 out of 99 of participants receiving placebo required antibiotics for acute otitis media. Qvarnberg 2001 reported that one out of 28 participants in the corticosteroid group and 0 out of 26 in the placebo group developed maxillary sinusitis based on ultrasound. Rahmati 2013 treated all participants with antibiotics and offered a second course of alternative antibiotics if the child failed to improve after three days but did not supply data on the number of children for whom this was the case.

\section{Quality of life measures and economic costs}

No data were reported in relation to quality of life measures, economic costs or adverse events necessitating discontinuation of treatment.

Puhakka 1998 reported that the steroid group had no clinical changes and no symptoms classifiable as adverse events. Nasal irritation and bleeding did not occur significantly more often in the steroid group than the placebo group. Qvarnberg 2001 and Rahmati 2013 did not record or report upon adverse events.

\section{ISCUSSION}

\section{Summary of main results}

This systematic review offers no evidence for benefit of intranasal corticosteroids for the common cold. The mean time to resolution of symptoms of the common cold was not significantly different in those participants using intranasal steroids compared to placebo in two of the studies included in this review. The symptom of sore 
throat had a longer duration in the corticosteroid group than the placebo group in one trial (Puhakka 1998), but this difference was not seen in the other trial (Qvarnberg 2001). The only trial to assess complete resolution of symptoms, Rahmati 2013, was of very poor quality and the outcome reporting was insufficient to allow us to report these data. Although they did demonstrate a significantly greater reduction in mean symptom severity score, this result must be interpreted in the context of a methodologically flawed trial performed in a population of patients that also included children with acute sinusitis.

In those participants shown to be rhinovirus-positive, duration of cough was shorter in the group receiving intranasal corticosteroids but there was no difference when all participants were assessed; no differences were seen in the trial by Qvarnberg 2001. The use of corticosteroids did not result in any adverse consequences in terms of bacteriological growth and did not result in significantly greater requirement for secondary antibiotic therapy. However, there were too few events in the combined studies to reliably detect a potential difference.

A significantly higher percentage of participants in the corticosteroid group were found to be rhinovirus-positive by viral culture in one trial (Puhakka 1998). This may imply that intranasal corticosteroids prolonged the duration of viable virus, which is of interest in the context of the known immunosuppressant actions of corticosteroids. However, prolonged presence of virus did not correlate with prolonged duration of symptoms.

\section{Overall completeness and applicability of evidence}

Only three trials of intranasal corticosteroids met the inclusion criteria for this review. One of these was a pilot study including only 54 participants (Qvarnberg 2001), and one was of very poor quality, with inadequate reporting of outcome measures (Rahmati 2013). This limits the conclusions that can be drawn. The data have limited applicability to older adults and there may be cultural differences that influence the predominantly self reported data from Finnish and Iranian patient groups. It is, of course, possible that a spray with inactive ingredients in itself is beneficial for the common cold. However, a recent systematic review found no convincing evidence of benefit of saline nasal spray for symptoms of upper respiratory tract infections (King 2015).

\section{Quality of the evidence}

The two double-blind trials included in this review failed to describe in detail the procedures followed for randomisation and blinding (Puhakka 1998; Qvarnberg 2001). However, both trials reported almost complete outcome data, were at low risk of reporting bias and described procedures for allocation concealment. Although no conflict of interest was reported, another potential source of bias may have been the sponsorship of one of the trials by the pharmaceutical company manufacturing the steroid spray and the inclusion of one of its employees on the authorship of the paper. The single-blind trial retrieved from our update of this review was at high risk of selection, performance and reporting bias, and results were not clearly presented (Rahmati 2013).

\section{Potential biases in the review process}

No potential biases are expected in this review process.

\section{Agreements and disagreements with other studies or reviews}

We excluded two trials that evaluated the clinical effectiveness of corticosteroids commenced in advance of inoculation with rhinovirus. Although the results of these studies have very limited applicability to clinical practice, the results are interesting in the context of the findings of our review. There were two trials involving 91 participants, of whom 75 became infected by rhinovirus. In Farr 1990, the active treatment group of 19 participants received a 10-day course of intranasal steroid beginning four days before inoculation and a three-day course of twice daily $30 \mathrm{mg}$ prednisolone beginning one day before inoculation. A significantly lower proportion of the corticosteroid group met the criteria for a cold and also believed that they had a cold. The reported severity of the cold was also lower on days one, two and five after inoculation. However, there was no difference in individual symptom score totals and summed symptom scores between corticosteroid and placebo groups, nor in total mean mucus weights and tissue use.

Gustafson 1996 examined the effect of $20 \mathrm{mg}$ prednisolone three times daily starting 11 hours before inoculation for five days in an active treatment group of 21 participants. In contrast to Farr 1990, they found no difference in the number of participants who met the criteria for a cold. There were no differences in total symptom scores, mucus production and tissue use between corticosteroid and placebo groups. They reported increased mean viral titres in the corticosteroid group but no difference in the frequency or duration of viral shedding. In summary, trials using inoculation of rhinovirus do not provide any consistent evidence of symptomatic benefit of corticosteroids in the common cold.

\section{AUTHORS' CONCLUSIONS}

\section{Implications for practice}

There is no evidence at present for benefit of intranasal corticosteroids for the common cold in adults, and the evidence for ben- 
efit in children is too low in quality to offer any useful additional information.

The included trials did not show any evidence of adverse effects of corticosteroid use. This suggests that patients using intranasal corticosteroids for other conditions need not discontinue them during a cold, although the effect on viral shedding and hence spreading to contacts is not known.

\section{Implications for research}

We found only three small trials addressing the effect of intranasal steroids for the common cold. A post-study sample size calculation based on the observed effect in one of the trials, Qvarnberg 2001 , suggests a minimum of 330 participants would be required, while the largest of the trials reported here had fewer than 200 participants. Based on this, further research is required to provide a clear answer to this clinical question, ideally large double-blind, placebo-controlled trials in both adult and paediatric populations, assessing clearly defined and replicable outcomes including duration of symptoms, days off school or work, and the impact upon shedding of active virus.

\section{ACKNOWLEDGEMENTS}

We would like to thank the British Society for Antimicrobial Chemotherapy for a seed grant to assess treatment of common upper respiratory tract infections with corticosteroids.

The University of Oxford Nuffield Department of Primary Care Health Sciences is part of the National Institute of Health Research School of Primary Care Research, which provides financial support for senior investigators who contributed to this article. The opinions expressed are those of the review authors and not of the Department of Health.

The review authors wish to thank the following people for commenting on the draft protocol: Morio Aihara, Jean-Michel Klossek, Nicola Principi, Sree Nair and Anca Zalmanovici. We thank the following people for commenting on the draft review: Amanda Young, Harri Hemilä, Rashmi Das, Sree Nair and Anca Zalmanovici; and we thank the following people for commenting on the draft update of this review: Jenny Negus, Amanda Roberts, Ravishankar and Anca Zalmanovici Trestioreanu.

\section{R E F E R E N C E S}

\section{References to studies included in this review}

Puhakka 1998 \{published data only\}

Puhakka T, Makela MJ, Malmstrom K, Uhari M, Savolainen

J, Terho EO, et al. The common cold: effects of intranasal

fluticasone propionate treatment. Journal of Allergy and Clinical Immunology 1998;101(6 Pt 1):726-31.

Qvarnberg 2001 \{published data only\}

Qvarnberg Y, Valtonen H, Laurikainen K. Intranasal beclomethasone dipropionate in the treatment of common cold. Rhinology 2001;39(1):9-12.

Rahmati 2013 \{published data only\}

Rahmati MB, Mohebi S, Shahmohammadi S, Rezai MS. Fluticasone nasal spray as an adjunct to amoxicillin for acute sinusitis in children: a randomized controlled trial. European Review for Medical and Pharmacological Sciences 2013;17(22):3068-72.

\section{References to studies excluded from this review}

Baccioglu Kavut 2013 \{published data only\}

Baccioglu Kavut A, Kalpaklı oğ lu F. Efficacy and safety of once daily triamcinolone acetonide aqueous nasal spray in adults with non-allergic and allergic rhinitis. Allergologia et Immunopathologia 2013;41(6):374-80.

Bellodi 2006 \{published data only\}

Bellodi S, Tosca MA, Pulvirenti G, Petecchia L, Serpero L, Silvestri M, et al. Activity of budesonide on nasal neutrophilic inflammation and obstruction in children with recurrent upper airway infections. A preliminary investigation. International Journal of Pediatric Otorhinolaryngology 2006;70(3):445-52.

Farr 1990 \{published data only\} Farr BM, Gwaltney JM Jr, Hendley JO, Hayden FG, Naclerio RM, McBride T, et al. A randomized controlled trial of glucocorticoid prophylaxis against experimental rhinovirus infection. Journal of Infectious Diseases 1990;162 (5):1173-7.

Gustafson 1996 \{published data only\} Gustafson LM, Proud D, Hendley JO, Hayden FG, Gwaltney JM Jr. Oral prednisone therapy in experimental rhinovirus infections. Journal of Allergy and Clinical Immunology 1996;97(4):1009-14.

\section{Keith 2012 \{published data only\}}

Keith PK, Dymek A, Pfaar O, Fokkens W, Yun Kirby S, Wu $\mathrm{W}$, et al. Fluticasone furoate nasal spray reduces symptoms of uncomplicated acute rhinosinusitis: a randomised placebo-controlled study. Primary Care Respiratory Journal: Journal of the General Practice Airways Group 2012;21(3): 267-75. [PUBMED: 22614920]

Lenander-Lumikari 1999 \{published data only\} Lenander-Lumikari M, Puhakka T, Makela MJ, Vilja P, Ruuskanen O, Tenovuo J. Effects of the common cold and intranasal fluticasone propionate treatment on mucosal host defense assessed by human saliva. Oral Surgery, Oral Medicine, Oral Pathology, Oral Radiology and Endodontology 1999;87(6):695-9. 
Mygind 1977 \{published data only\}

Mygind N. Beclomethasone dipropionate in intranasal treatment. Nouvelle Presse Medicale 1977;6(15):1319-21.

Peynegre 2005 \{published data only\}

Peynegre R, Dessanges JF, Bruhwyler J, Concas V. Efficacy of Derinox assessed with one PNIF (peak nasal inspiratory flow) in patients suffering from common cold. Annales d'Oto-laryngologie et de Chirurgie Cervico Faciale: Bulletin de la Societe d'Oto-laryngologie des Hopitaux de Paris 2005;122 (5):246-55.

Proud 1994 \{published data only\} Proud D, Gwaltney JM Jr, Hendley JO, Dinarello CA, Gillis S, Schleimer RP. Increased levels of interleukin1 are detected in nasal secretions of volunteers during experimental rhinovirus colds. Journal of Infectious Diseases 1994;169(5):1007-13.

Reinert 1991 \{published data only\} Reinert P, Narcy P, Paliwoda A, Rouffiac E. Evaluation of tixocortol pivalate-neomycin combination versus $++\mathrm{a}$ placebo excipient in acute rhinopharyngitis in children. Annales de Pediatrie 1991;38(7):503-8.

Tugrul 2014 \{published data only\} Tugrul S, Dogan R, Eren SB, Meric A, Ozturan O. The use of large volume low pressure nasal saline with fluticasone propionate for the treatment of pediatric acute rhinosinusitis. International Journal of Pediatric Otorhinolaryngology 2014;78(8):1393-9. [PUBMED: 24972936]

\section{Additional references}

\section{Adams 1999}

Adams PF, Hendershot GE, Marano MA, Centers for Disease Control and Prevention/National Center for Health Statistics. Current estimates from the National Health Interview Survey, 1996. Vital \& Health Statistics - Series 10: Data From the National Health Survey 1999;200:1-203.

\section{Bramley 2002}

Bramley TJ, Lerner D, Sames M. Productivity losses related to the common cold. Journal of Occupational \& Environmental Medicine 2002;44(9):822-9.

\section{Fendrick 2003}

Fendrick AM. Viral respiratory infections due to rhinoviruses: current knowledge, new developments. American Journal of Therapeutics 2003;10(3):193-202.

\section{Hayward 2009}

Hayward G, Thompson M, Heneghan C, Perera R, Del Mar C, Glasziou P. Corticosteroids for pain relief in sore throat: systematic review and meta-analysis. BMJ (Clinical Research ed.) 2009;339:b2976. [PUBMED: 19661138]

\section{Higgins 2011}

Higgins JPT, Green S (editors). Cochrane Handbook for Systematic Reviews of Interventions Version 5.1.0 [updated March 2011]. The Cochrane Collaboration, 2011. Available from www.cochrane-handbook.org.

\section{Kaiser 1996}

Kaiser L, Lew D, Hirschel B, Auckenthaler R, Morabia A, Heald A, et al. Effects of antibiotic treatment in the subset of common-cold patients who have bacteria in nasopharyngeal secretions [see comment]. Lancet 1996;347 (9014):1507-10.

King 2015

King D, Mitchell B, Williams CP, Spurling GKP. Saline nasal irrigation for acute upper respiratory tract infections. Cochrane Database of Systematic Reviews 2015, Issue 4. DOI: 10.1002/14651858.CD006821.pub3

\section{Lefebvre 2011}

Lefebvre C, Manheimer E, Glanville J. Chapter 6: Searching for studies. In: Higgins JPT, Green S (editors). Cochrane Handbook for Systematic Reviews of Interventions Version 5.1.0 [updated March 2011]. The Cochrane Collaboration, 2011. Available from www.cochrane-handbook.org.

\section{Makela 1998}

Makela MJ, Puhakka T, Ruuskanen O, Leinonen M, Saikku P, Kimpimaki M, et al. Viruses and bacteria in the etiology of the common cold. Journal of Clinical Microbiology 1998; 36(2):539-42.

\section{Mygind 2001}

Mygind N, Nielsen LP, Hoffmann HJ, Shukla A, Blumberga G, Dahl R, et al. Mode of action of intranasal corticosteroids. Journal of Allergy \& Clinical Immunology 2001;108(Suppl 1):16-25.

\section{Russell 2011}

Russell KF, Liang Y, O’Gorman K, Johnson DW, Klassen TP. Glucocorticoids for croup. Cochrane Database of Systematic Reviews 2011, Issue 1. DOI: 10.1002/ 14651858.CD001955.pub3

\section{Wiest 2011}

Wiest E, Jones JS. Towards evidence-based emergency medicine: best BETs from the Manchester Royal Infirmary. BET 1: Use of non-sedating antihistamines in the common cold. Emergency Medicine Journal 2011;28(7):632-3. [PUBMED: 21700747]

\section{Zalmanovici 2013}

Zalmanovici Trestioreanu A, Yaphe J. Intranasal steroids for acute sinusitis. Cochrane Database of Systematic Reviews 2013, Issue 12. DOI: 10.1002/14651858.CD005149.pub4

\section{References to other published versions of this review}

\section{Hayward 2009b}

Hayward G, Thompson MJ, Heneghan CJ, Perera R, Del Mar CB, Glasziou PP. Corticosteroids for the common cold. Cochrane Database of Systematic Reviews 2009, Issue 4. DOI: $10.1002 / 14651858 . C D 008116$

\section{Hayward 2012}

Hayward G, Thompson MJ, Perera R, Del Mar CB, Glasziou PP, Heneghan CJ. Corticosteroids for the common cold. Cochrane Database of Systematic Reviews 2012, Issue 8. DOI: 10.1002/14651858.CD008116.pub2

* Indicates the major publication for the study 


\section{CHARACTERISTICS OF STUDIES}

\section{Characteristics of included studies [ordered by study ID]}

\section{Puhakka 1998}

Methods

Participants

Interventions

Notes

\section{Risk of bias}

Outcomes
200 "young adults" (59 males of mean age 24.0 years \pm 2.7 and 141 females of mean age 24.1 years \pm 3.6 ) with watery or purulent rhinitis and at least 1 of: cough, headache, hoarseness, myalgia, nasal congestion, oral temperature higher than $37.0^{\circ} \mathrm{C}$ or throat soreness were recruited. A total of 199 participants completed the study. Participants were recruited from the general population in Finland through advertisements and contact persons. Participants had to be healthy and without antibiotics for 4 weeks preceding entry into the study. Exclusion criteria - allergic rhinitis, history of chronic or recurrent sinusitis or lower respiratory tract disease, major nasal septal deviation, nasal polyposis, pregnancy, lactation

Fluticasone propionate nasal spray daily dose $800 \mu \mathrm{g}$ (administered as 2 puffs of $50 \mu \mathrm{g}$ to each nostril 4 times a day at equal intervals during waking hours). Administration began 24 to 48 hours after onset of symptoms and continued for 6 days. Placebo spray was identical to the study drug without fluticasone propionate

Symptom severity scores via diary card - twice daily from days 1 to 6 then in the evening from days 7 to 20 , assessing the severity of the symptoms of watery rhinitis, purulent rhinitis, nasal congestion, nasal irritation, nasal bleeding, blood in nasal mucous, cough, sputum, headache, fever, throat soreness, hoarseness, sweating, myalgia, lethargy. Oral temperature record on days 1 to 6 and then if participant felt feverish. Absence from study or work. Consumption of paracetamol tablets. Nasopharyngeal aspirate on days 1 and 7 for rhinovirus culture, rhinovirus PCR and bacterial culture

Paracetamol was permitted in participants with fever or pain. However, drugs affecting nasal or lung function (including over-the-counter medications) were not allowed during the study

Study drug and placebo were supplied by Glaxo Research and development

\begin{tabular}{l|l|l}
\hline Bias & Authors' judgement & Support for judgement \\
\hline $\begin{array}{l}\text { Random sequence generation (selection } \\
\text { bias) }\end{array}$ & Unclear risk & $\begin{array}{l}\text { The method of randomisation is not de- } \\
\text { scribed }\end{array}$ \\
\hline Allocation concealment (selection bias) & Low risk & $\begin{array}{l}\text { Study drug and placebo contained identical } \\
\text { ingredients with the exception of fluticas- } \\
\text { one propionate. Steroid and placebo sup- } \\
\text { plied by pharmaceutical company. Authors } \\
\text { do not explicitly comment on the nature of } \\
\text { the packaging }\end{array}$
\end{tabular}




\section{Puhakka 1998 (Continued)}

Blinding (performance bias and detection Unclear risk bias)

All outcomes

Incomplete outcome data (attrition bias) Low risk All outcomes

Selective reporting (reporting bias) Low risk
High risk
Authors state that the study was doubleblind but do not give further detail regarding this

Only 1 patient $(0.5 \%)$ from the placebo group did not complete the study. They were excluded for improper use of study medication

Reasonable reporting of outcomes, although often data were described in the text rather than presented and standard deviations were not mentioned. The use of study medication (i.e. compliance with study) was assessed but not reported

Other bias
Paracetamol use was recorded but not controlled: 141 tablets were used in the corticosteroid group and 170 in the placebo group. This difference may have affected symptom scores

Reports "no differences in demographic characteristics"
Comparability of groups on different prog- Low risk nostic characteristics
Randomised, placebo-controlled, double-bind, parallel-group design

54 patients ( 49 women, 5 men) over 18 years of age with symptoms of acute common cold having lasted from 1 to 3 days. Recruited from hospital staff in central Finland. Mean age 40.3 , range 23 to 57 years. Exclusion criteria: chronic systemic diseases, ongoing treatment with corticosteroids, pregnancy

Interventions

Beclomethasone dipropionate + lactose nasal spray $400 \mu \mathrm{g}$ daily dose - 2 puffs of $100 \mu \mathrm{g}$ to each nostril once daily. Placebo spray lactose alone

Outcomes

Symptom diaries - recording severity of nasal blockage, rhinorrhoea, nasal itching, sneezing, cough, sore throat, hoarseness. Also, sum of symptom scores recorded. Rhinoscopic and ultrasonographic (of the maxillary sinuses) findings at days 1, 7 and 14

Notes

Orion Corporation Ltd supplied the study drugs

\section{Risk of bias}

Bias
Authors' judgement
Support for judgement 


\section{Qvarnberg $2001 \quad$ (Continued)}

\begin{tabular}{|c|c|c|}
\hline $\begin{array}{l}\text { Random sequence generation (selection } \\
\text { bias) }\end{array}$ & Unclear risk & $\begin{array}{l}\text { Randomisation code used - no further de- } \\
\text { tails supplied }\end{array}$ \\
\hline Allocation concealment (selection bias) & Low risk & $\begin{array}{l}\text { Same inhaler used for both placebo and } \\
\text { BDP administration. Non-active ingredi- } \\
\text { ents the same }\end{array}$ \\
\hline $\begin{array}{l}\text { Blinding (performance bias and detection } \\
\text { bias) } \\
\text { All outcomes }\end{array}$ & Unclear risk & $\begin{array}{l}\text { Double-blind design stated. Data entry was } \\
\text { blinded but no further details regarding this } \\
\text { reported }\end{array}$ \\
\hline $\begin{array}{l}\text { Incomplete outcome data (attrition bias) } \\
\text { All outcomes }\end{array}$ & Low risk & $\begin{array}{l}2 / 54 \text { patients discontinued the study, } 1 \\
\text { from each group }\end{array}$ \\
\hline Selective reporting (reporting bias) & Low risk & $\begin{array}{l}\text { All outcomes measured were reported in } \\
\text { either text or data }\end{array}$ \\
\hline Other bias & Unclear risk & $\begin{array}{l}\text { A high percentage of patients had been } \\
\text { treated for maxillary sinusitis previously: } \\
19 / 26 \text { in placebo and } 14 / 28 \text { in corticos- } \\
\text { teroid groups }\end{array}$ \\
\hline $\begin{array}{l}\text { Comparability of groups on different prog- } \\
\text { nostic characteristics }\end{array}$ & Low risk & $\begin{array}{l}\text { No statistically significant differences be- } \\
\text { tween groups at baseline on important } \\
\text { prognostic characteristics, e.g. duration of } \\
\text { cold symptoms before entry, symptom pro- } \\
\text { file, rhinoscopy and ultrasonography ap- } \\
\text { pearances, patient characteristics. No base- } \\
\text { line data were presented to support this }\end{array}$ \\
\hline
\end{tabular}

Rahmati 2013

Methods

Participants

Interventions
Single-blind, randomised trial comparing intranasal steroids and oral amoxicillin to oral amoxicillin alone

100 children aged 2 to 14 with common colds lasting more than 10 days with nasal or postnasal discharge or common cold lasting less than 10 days with purulent nasal discharge and 3 to 4 days of rectally recorded fever greater than $39^{\circ} \mathrm{C}$. Exclusion criteria: allergic rhinitis, nasal obstruction due to deviated nasal septum, nasal polyps, lack of parental co-operation, contraindications to use of the intervention medication, wound or lesion in the nasal mucosa. Children were recruited from outpatient clinics at the paediatric hospital in Iran

$50 \mu \mathrm{g}$ of fluticasone propionate nasal spray $(50 \mu \mathrm{g} / \mathrm{puff}$, Flixonase, GSK) twice daily for 14 days Unclear which nostril was used

Both groups received amoxicillin 80 to $100 \mathrm{mg} / \mathrm{kg} /$ day 
Rahmati 2013 (Continued)

Outcomes

Severity of symptoms as documented by blinded healthcare workers by phone or face to face discussion on day 4 of the intervention and on days 10 to 14

Severity of symptoms was calculated for each symptom as 0 for not affected, 1 for very little problem, 2 for mild problem, 3 for moderately bad, 4 for bad and 5 for severe

Total (mean) symptom severity score reported, however the authors do not describe how this is calculated. They also do not state how many days post-intervention the individual symptom scores were reported - this could be anywhere from 4 to 14 days after recruitment

Complete recovery of symptoms - based, according to personal communication with authors, on clinical assessment and patient self report, however, unclear method of calculation and time point of assessment

Relative recovery of symptoms - the authors state in direct communication that this was defined as recovery of associated symptoms such as cough, headache, malaise, facial pain, irritability but it remains unclear how this was calculated and the time point of assessment

Notes

Risk of bias

Bias

Authors' judgement

Support for judgement

Random sequence generation (selection Low risk

Communication with the authors: com-

bias)

puter-generated randomisation used

Allocation concealment (selection bias) High risk

No control nasal spray used

Blinding (performance bias and detection High risk

bias)

All outcomes

Single-blind study - outcome assessors were blinded but the majority of the measures were based on patient self report

Incomplete outcome data (attrition bias) Low risk

All outcomes

Outcome data were presented for all the children recruited in each arm

The paper reports that patients were excluded if they showed no improvement by day 4 of the intervention Direct communication with authors revealed that no children were excluded for this reason

Selective reporting (reporting bias) High risk

Very limited reporting of outcome measures

Other bias

High risk

If no improvement was seen in fever nasal congestion or cough, or if exacerbation of disease was evident, patients were reassessed and the antibiotics were changed if necessary. Following direct communication with the authors they stated that "As a whole, patients were assessed again and the antibi- 
otics were changed if necessary at any time. In fact, most of the patient had received a different treatment, if they did not response to the first line antibiotic therapy after 3 days of the initial treatment." The type and duration of antibiotic usage if changed is not reported and so may have introduced performance bias

The type and duration of antibiotics once changed is not reported and so may have introduced performance bias

Comparability of groups on different prog- Low risk nostic characteristics
Symptom severity scores were $22.46+/-2$. 61 and $23.50+/-3.19$ before treatment, however it is unclear how this was calculated

The authors state in the text that "clinical features were almost similar at baseline of the study...and the differences between them are negligible" but the table they refer to in support of this statement does not offer any relevant data

In personal communication the authors stated that there were no statistical differences in baseline prognostic characteristics

BDP: beclomethasone dipropionate

PCR: polymerase chain reaction

\section{Characteristics of excluded studies [ordered by study ID]}

\begin{tabular}{l|l}
\hline Study & Reason for exclusion \\
\hline Baccioglu Kavut 2013 & Defined non-allergic rhinitis as those cases that were not infection \\
\hline Bellodi 2006 & Population was children with chronic nasal obstruction \\
\hline Farr 1990 & Experimentally induced rhinovirus infection. Steroid administered before inoculation \\
\hline Gustafson 1996 & Experimentally induced rhinovirus infection. Steroid administered before inoculation \\
\hline Keith 2012 & Symptoms lasted for longer than 10 days - beyond the natural history of the common cold \\
\hline Lenander-Lumikari 1999 & No relevant outcome measures reported. Same study population as Puhakka 1998 \\
\hline $\begin{array}{l}\text { Corticosteroids for the common cold (Review) } \\
\text { Copyright @ 2016 The Cochrane Collaboration. Published by John Wiley \& Sons, Ltd. }\end{array}$
\end{tabular}


(Continued)

Mygind 1977 Review article focusing on perennial and allergic rhinitis (no abstract available initially and so we obtained full text)

Peynegre 2005

No direct comparison between steroid and placebo - groups treated otherwise unequally in terms of type of vasoconstrictor and presence/absence of mucolytic

Proud 1994

Experimentally induced rhinovirus infection. Steroid administered before inoculation. Same patient population as Farr et al but examining biochemical markers rather than symptoms

Reinert 1991

No direct comparison between steroid and placebo - steroid group also received intranasal neomycin

Tugrul 2014

Symptoms lasted for longer than 10 days - beyond the natural history of the common cold 


\section{DATA ANDANALYSES}

\section{Comparison 1. Rhinovirus infection}

\begin{tabular}{lcccc} 
Outcome or subgroup title & $\begin{array}{c}\text { No. of } \\
\text { studies }\end{array}$ & $\begin{array}{c}\text { No. of } \\
\text { participants }\end{array}$ & Statistical method & Effect size \\
\hline $\begin{array}{l}\text { 1 Number of patients } \\
\text { with rhinovirus-positive } \\
\text { nasopharyngeal aspirates at day } \\
7 \text { of treatment }\end{array}$ & 1 & 199 & Risk Ratio (M-H, Fixed, 95\% CI) & $0.99[0.73,1.34]$ \\
\hline
\end{tabular}

Analysis I.I. Comparison I Rhinovirus infection, Outcome I Number of patients with rhinovirus-positive nasopharyngeal aspirates at day 7 of treatment.

Review: Corticosteroids for the common cold

Comparison: | Rhinovirus infection

Outcome: I Number of patients with minovirus-positive nasopharyngeal aspirates at day 7 of treatment

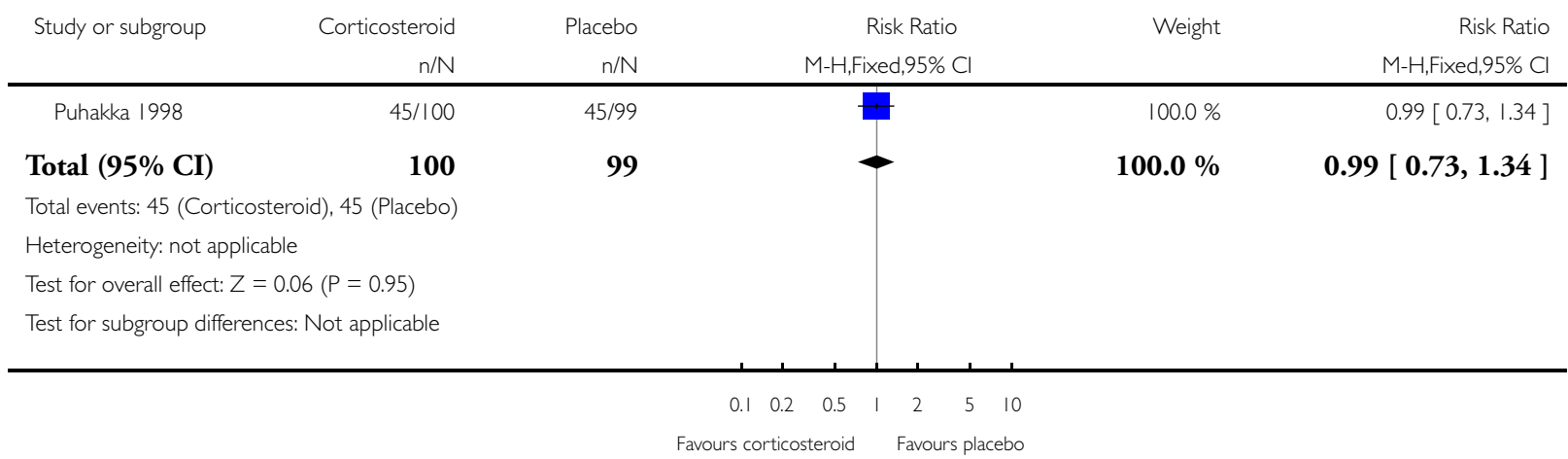




\section{A P P E N D I C ES}

\section{Appendix I. MEDLINE and CENTRAL search strategy}

1 Common Cold/ (3092)

2 common cold*.tw. (2266)

3 coryza.tw. (333)

4 Respiratory Tract Infections/ (27457)

5 upper respiratory tract infection*.tw. (3093)

6 upper respiratory infection*.tw. (1605)

7 (uri or urti).tw. (795)

8 Epiglottitis/ (826)

9 epiglottitis.tw. (1100)

10 Rhinitis/ (7046)

11 rhinitis.tw. (15548)

12 Nasopharyngitis/ (227)

13 (rhinopharyngitis or nasopharyngitis).tw. (354)

14 Nasal Obstruction/ (2895)

15 Sneezing/ (674)

16 (rhinorrhoea or rhinorrhoea).tw. (2839)

17 ((nasal or nose*) adj2 (runny or running or congest* or blocked or discharg*)).tw. (2790)

18 Rhinovirus/ (2389)

19 rhinovir*.tw. (2747)

20 coronavirus/ or coronavirus 229e, human/ or coronavirus nl63, human/ or coronavirus oc43, human/ (1001)

21 coronavir*.tw. (5880)

22 Adenoviruses, Human/ (5968)

23 adenoviridae infections/ or adenovirus infections, human/ (5437)

24 adenovir*.tw. (35954)

25 Picornaviridae Infections/ (1023)

26 Enterovirus Infections/ (3197)

27 Coxsackievirus Infections/ (3252)

28 Echovirus Infections/ (917)

29 enterovirus/ or enterovirus a, human/ or exp enterovirus b, human/ or enterovirus c, human/ or enterovirus d, human/ (8810)

30 (pircornavir* or enterovir* or echovir* or coxsackie*).tw. (10659)

31 respiratory syncytial viruses/ or respiratory syncytial virus, human/ (5432)

32 Respiratory Syncytial Virus Infections/ (3715)

33 (respiratory syncytial virus infection* or rsv).tw. (6792)

34 parainfluenza virus 2 , human/ or parainfluenza virus 4 , human/ (246)

35 parainfluenza virus 1 , human/ or parainfluenza virus 3, human/ (3514)

36 parainfluenza*.tw. (4196)

37 Epstein-Barr Virus Infections/ (4070)

38 (epstein-barr or epstein barr or ebv).tw. (25436)

39 Orthomyxoviridae/ (9572)

40 Orthomyxoviridae Infections/ (5322)

41 exp Influenzavirus A/ (21562)

42 exp Influenzavirus B/ (2514)

43 Influenzavirus C/ (260)

44 (influenzavirus* or influenza virus*).tw. (18748)

45 orthomyxovir*.tw. (303)

46 Paramyxoviridae Infections/ (2177)

47 paramyxovir*.tw. (2411)

48 Cytomegalovirus Infections/ (17819)

49 cytomegalovir*.tw. (28732)

Corticosteroids for the common cold (Review)

Copyright @ 2016 The Cochrane Collaboration. Published by John Wiley \& Sons, Ltd. 
50 simplexvirus/ or herpesvirus 1, human/ (22653)

51 Herpesvirus 4, Human/ (18492)

52 or/1-51 (238889)

53 exp Glucocorticoids/ (144252)

54 glucocorticoid*.tw,nm. (70536)

55 exp Hydroxycorticosteroids/ (114224)

56 hydroxycorticosteroid*.tw,nm. (6472)

57 exp Pregnenediones/ (151889)

58 pregnenedione*.tw,nm. (1896)

59 pregnenolone*.tw,nm. (6061)

60 hydrocortisone.tw,nm. (60234)

61 hydroxypregnenolone.tw,nm. (846)

62 tetrahydrocortisol.tw,nm. (424)

63 cortodoxone.tw,nm. (746)

64 cortisone.tw,nm. (17357)

65 corticosterone.tw,nm. (25049)

66 triamcinolone.tw,nm. (8007)

67 prednisone.tw,nm. (39528)

68 prednisolone.tw,nm. (33196)

69 paramethasone.tw,nm. (218)

70 methylprednisolone.tw,nm. (18039)

71 dexamethasone.tw,nm. (50373)

72 clobetasol.tw,nm. (1031)

73 beclomethasone.tw,nm. (3165)

74 betamethasone.tw, nm. (5764)

75 budesonide.tw, nm. (3773)

76 corticosteroid*.tw,nm. (61498)

77 steroid*.tw,nm. (223268)

78 (efcortesol or hydrocortone or solu-cortef).tw,nm. (25)

79 (betnelan or betnesol).tw,nm. (25)

80 (deflazacort or calcort).tw,nm. (389)

81 (medrone or solu-medrone or depo-medrone).tw,nm. (12)

82 kenalog.tw,nm. (148)

83 (novolizer or pulmicort or symbicort).tw,nm. (248)

84 (beclometasone or aerobec or asmabec or beclazone or becodisks or becotide or clenil modulite or qvar or becloforte).tw,nm. (221)

85 or/53-84 (530327)

8652 and 85 (8306)

87 randomized controlled trial.pt. (299024)

88 controlled clinical trial.pt. (81706)

89 randomized.ab. (206825)

90 placebo.ab. (121696)

91 clinical trials as topic.sh. (152139)

92 randomly.ab. (150335)

93 trial.ti. (88765)

9487 or 88 or 89 or 90 or 91 or 92 or 93 (696129)

95 exp animals/ not humans.sh. (3533521)

9694 not 95 (643057)

9786 and 96 (1372)

Corticosteroids for the common cold (Review) 


\section{Appendix 2. EMBASE.com search strategy}

\#58. \#54 AND \#57 3,854 25 Feb 2011

\#57. \#55 OR \#56 912,654 25 Feb 2011

\#56. random*:ab,ti OR placebo* OR factorial*:ab,ti OR crossover*:ab,ti OR 'cross over':ab,ti OR 'cross-over':ab,ti OR volunteer*:ab,ti OR assign*:ab,ti OR allocat*:ab,ti OR ((singl* OR doubl*) NEAR/1 blind*):ab,ti AND [embase]/lim 881,603 25 Feb 2011

\#55. 'randomized controlled trial'/exp OR 'single blind procedure'/exp OR 'double blind procedure'/exp OR 'crossover procedure'/exp AND [embase]/lim 237,517 25 Feb 2011

\#54. \#41 AND \#53 18,703 25 Feb 2011

\#53. \#42 OR \#43 OR \#44 OR \#45 OR \#46 OR \#47 OR \#48 OR \#49 OR \#50 OR \#51 OR \#52 620,492 25 Feb 2011

\#52. beclometasone:ab,ti OR aerobec:ab,ti OR asmabec:ab,ti OR beclazone:ab,ti OR becodisks:ab,ti OR becotide:ab,ti OR 'clenil modulite':ab,ti OR qvar:ab,ti OR becloforte:ab,ti AND [embase]/lim 42125 Feb 2011

\#51. novolizer:ab,ti OR pulmicort:ab,ti OR symbicort:ab,ti AND [embase]/lim 29225 Feb 2011

\#50. kenalog:ab,ti AND [embase]/lim 11725 Feb 2011

\#49. medrone:ab,ti OR 'solu-medrone':ab,ti OR 'depo-medrone':ab,ti AND [embase]/lim 1425 Feb 2011

\#48. deflazacort:ab,ti OR calcort:ab,ti AND [embase]/lim 39425 Feb 2011

\#47. efcortesol:ab,ti OR hydrocortone:ab,ti OR 'solu cortef':ab,ti OR betnelan:ab,ti OR betnesol:ab,ti AND [embase]/lim 4925 Feb 2011

\#46. steroid*:ab,ti OR hydrocortisone:ab,ti OR hydroxypregnenolone:ab,ti OR pregnenolone:ab,ti OR tetrahydrocortisol:ab,ti OR cortodoxone:ab,ti OR cortisone:ab,ti OR corticosterone:ab,ti OR

triamcinolone:ab,ti OR prednisone:ab,ti OR prednisolone:ab,ti OR paramethasone:ab,ti OR methylprednisolone:ab,ti OR dexamethasone:ab,ti OR clobetasol:ab,ti OR beclomethasone:ab,ti OR

beclometasone:ab,ti OR betamethasone:ab,ti OR budesonide:ab,ti AND [embase]/lim 255,337 25 Feb 2011

\#45. 'cortodoxone'/de AND [embase]/lim 1,260 25 Feb 2011

\#44. 'pregnane derivative'/de AND [embase]/lim 52825 Feb 2011

\#43. corticosteroid*:ab,ti OR glucocorticoid*:ab,ti OR hydrocorticosteroid*:ab,ti OR hyroxcorticosteroid*:ab,ti AND [embase]/lim 105,815 25 Feb 2011

\#42. 'corticosteroid'/exp AND [embase]/lim 495,099 25 Feb 2011

\#41. \#1 OR \#2 OR \#3 OR \#4 OR \#5 OR \#6 OR \#7 OR \#8 OR \#9 OR \#10 OR \#11 OR \#12 OR \#13 OR \#14 OR \#15 OR \#16 OR \#17 OR \#18 OR\#19 OR \#20 OR \#21 OR\#22 OR \#23 OR \#24 OR \#25 OR \#26 OR \#27 OR \#28 OR \#29 OR \#30 OR \#31 OR \#32 OR \#33 OR \#34 OR \#35 OR \#36 OR \#37 OR \#38 OR \#39 OR \#40 164,080 25 Feb 2011

\#40. 'herpes simplex virus 1'/de AND [embase]/lim 12,865 25 Feb 2011

\#39. 'simplexvirus'/de AND [embase]/lim 325 Feb 2011

\#38. cytomegalovir*:ab,ti AND [embase]/lim 27,461 25 Feb 2011

\#37. 'cytomegalovirus infection'/de AND [embase]/lim 16,718 25 Feb 2011

\#36. paramyxovir*:ab,ti AND [embase]/lim 1,988 25 Feb 2011

\#35. 'paramyxovirus infection'/de AND [embase]/lim $925 \mathrm{Feb} 2011$

\#34. influenzavir*:ab,ti OR 'influenza virus':ab,ti OR 'influenza viruses':ab,ti AND [embase]/lim 925 Feb 2011

\#33. 'influenza virus a'/exp OR 'influenza virus b'/de OR 'influenza virus c'/de AND [embase]/lim 15,442 25 Feb 2011

\#32. orthomyxovir*:ab,ti AND [embase]/lim 24925 Feb 2011

\#31. 'orthomyxovirus infection'/de OR 'orthomyxovirus'/de AND [embase]/lim 63825 Feb 2011

\#30. 'epstein barr':ab,ti OR 'epstein-barr':ab,ti OR ebv:ab,ti AND [embase]/lim 24,877 25 Feb 2011

\#29. 'epstein barr virus infection'/de AND [embase]/lim 52225 Feb 2011

\#28. parainfluenza*:ab,ti AND [embase]/lim 3,453 25 Feb 2011

\#27. 'parainfluenza virus'/exp AND [embase]/lim 4,200 25 Feb 2011

\#26. 'respiratory syncytial virus':ab,ti OR 'respiratory syncytial viruses':ab,ti OR rsv:ab,ti AND [embase]/lim 9,130 25 Feb 2011

\#25. 'respiratory syncytial pneumovirus'/de OR 'respiratory syncytial virus infection'/de AND [embase]/lim 8,874 25 Feb 2011

\#24. picornavir*:ab,ti OR enterovir*:ab,ti OR echovir*ab,ti OR coxsackie*:ab,ti AND [embase]/lim AND [2007-2011]/py 2,146 25 Feb 2011

\#23. 'picornavirus infection'/de OR 'enterovirus infection'/de OR 'coxsackie virus infection'/de OR 'echovirus infection'/de AND [embase]/lim AND [2007-2011]/py 53825 Feb 2011

\#22. adenovir*:ab,ti AND [embase]/lim AND 8,654 25 Feb 2011 [2007-2011]/py

\#21. 'human adenovirus infection'/de AND [embase]/lim AND [2007-2011]/py 1925 Feb 2011 
\#20. 'human adenovirus'/exp AND [embase]/lim AND [2007-2011]/py 29025 Feb 2011

\#19. coronavir*:ab,ti AND [embase]/lim AND [2007-2011]/py 1,238 24 Feb 2011

\#18. 'coronavirus'/de OR 'sars coronavirus'/de AND [embase]/lim AND [2007-2011]/py 1,515 24 Feb 2011

\#17. rhinovir*ab,ti AND [embase]/lim AND [2007-2011]/py 78724 Feb 2011

\#16. 'rhinovirus infection'/de OR 'human rhinovirus'/de AND [embase]/lim AND [2007-2011]/py 38924 Feb 2011

\#15. sneez*:ab,ti OR rhinorrhea:ab,ti OR rhinorrhoea:ab,ti AND [embase]/lim AND [2007-2011]/py 1,167 24 Feb 2011

\#14. 'rhinorrhea'/de AND [embase]/lim AND [2007-2011]/py 1,615 24 Feb 2011

\#13. 'sneezing'/de AND [embase]/lim AND [2007-2011]/py 99924 Feb 2011

\#12. ((nasal OR nose*) NEAR/2 (runny OR running OR congest* OR blocked OR discharg*)):ab,ti AND [2007-2011]/py 1,001 24

Feb 2011

\#11. 'nose obstruction'/de AND [embase]/lim 4,571 24 Feb 2011

\#10. rhinitis:ab,ti OR nasopharyngitis:ab,ti OR rhinopharyngitis:ab,ti AND [embase]/lim 17,156 24 Feb 2011

\#9. 'rhinitis'/de OR 'rhinopharyngitis'/de OR 'nose infection'/de AND [embase]/lim 13,616 24 Feb 2011

\#8. epiglottitis:ab,ti AND [embase]/lim 94424 Feb 2011

\#7. 'epiglottitis'/exp AND [embase]/lim 1,349 24 Feb 2011

\#6. uri:ab,ti OR urti:ab,ti AND [embase]/lim 87924 Feb 2011

\#5. 'upper respiratory tract infection':ab,ti OR 'upper respiratory tract infections':ab,ti OR 'upper respiratory infection':ab,ti OR 'upper respiratory infections':ab,ti AND [embase]/lim 4,873 24 Feb 2011

\#4. 'upper respiratory tract infection'/de AND [embase]/lim 10,775 24 Feb 2011

\#3. coryza:ab,ti AND [embase]/lim $19624 \mathrm{Feb} 2011$

\#2. 'common cold':ab,ti OR 'common colds':ab,ti AND [embase]/lim 2,062 24 Feb 2011

\#1. 'common cold'/de AND [embase]/lim 3,684 24 Feb 2011

\section{F E E D B A C K}

\section{Corticosteroids for the common cold, 2 November 2015}

\section{Summary}

Comment: I am a layman but I've noted that steroid inhalers usually take 8 weeks, 2 weeks orally. If this is correct results are unsurprising. How about a trial of steroids for those who get regular colds - either those in large population exposure or, perhaps more likely beneficiaries, the vulnerable to infections. Or even mass-population trialling, assuming limited side effects of continual use.

Paul Harris

I agree with the conflict of interest statement below:

I certify that I have no affiliations with or involvement in any organization or entity with a financial interest in the subject matter of my feedback.

\section{Reply}

Our systematic review asked whether steroids could improve symptoms of the common cold, and did not address the question of whether regular steroid use could prevent the common cold. However, we excluded two trials where the participants were given oral or intra-nasal steroids before being experimentally infected with a virus known to cause colds and we describe the findings of these trials in our discussion section. Both of these trials had small numbers of participants and they offered inconsistent evidence of a benefit of preventative steroid therapy. Therefore, a larger trial is needed to understand whether this approach might be beneficial, but there are health risks associated with long term steroid use, particularly oral steroid use, which might well make this approach unpopular even if it were shown to be effective.

\section{Contributors}

Gail Hayward

Corticosteroids for the common cold (Review) 


\section{WHAT'S NEW}

Last assessed as up-to-date: 19 May 2015.

\begin{tabular}{l|l|l}
\hline Date & Event & Description \\
\hline 11 March 2016 & Feedback has been incorporated & Feedback comment and reply added to the review. \\
\hline
\end{tabular}

\section{H I S T O R Y}

Protocol first published: Issue 4, 2009

Review first published: Issue 8, 2012

\begin{tabular}{lll}
\hline Date & Event & Description \\
\hline 19 May 2015 & New search has been performed & $\begin{array}{l}\text { Searches updated. We included one new trial (Rahmati } \\
\text { 2013), and excluded three new trials (Baccioglu Kavut } \\
\text { 2013; Keith 2012; Tugrul 2014). }\end{array}$ \\
\hline 19 May 2015 & $\begin{array}{l}\text { New citation required but conclusions have not } \\
\text { changed }\end{array}$ & $\begin{array}{l}\text { The addition of one further trial does not change the } \\
\text { conclusions of the review }\end{array}$ \\
\hline 6 September 2012 & Amended & Acknowledgements section amended. \\
\hline 16 June 2010 & Amended & Contact details updated. \\
\hline
\end{tabular}

\section{CONTRIBUTIONS OFAUTHORS}

Gail Hayward wrote the review. The manuscript was revised by all review authors.

\section{DECLARATIONS OF INTEREST}

Gail Hayward: none known

Matthew J Thompson: none known

Rafael Perera: none known

Chris B Del Mar: none known

Paul P Glasziou: none known

Carl J Heneghan: none known 


\section{SOURCES OF SUPPORT}

\section{Internal sources}

- No sources of support supplied

\section{External sources}

- British Society for Antimicrobial Chemotherapy, UK.

Funding for this work was provided in part by a Systematic Review Grant (GA722SRG) from the British Society for Antimicrobial Chemotherapy

\section{DIFFERENCESBETWEEN PROTOCOLANDREVIEW}

We have added an additional exclusion criterion as follows: "We also excluded trials where the common cold was experimentally induced if the intervention was initiated before the cold was induced." We made this decision once the range of eligible papers was established as we had not anticipated trials using experimentally induced infections.

\section{NDEX TERMS}

\section{Medical Subject Headings (MeSH)}

Administration, Intranasal; Adrenal Cortex Hormones [*therapeutic use]; Androstadienes [*therapeutic use]; Beclomethasone [ ${ }^{*}$ therapeutic use]; Common Cold [* drug therapy]; Fluticasone [therapeutic use]; Randomized Controlled Trials as Topic; Treatment Outcome

\section{MeSH check words}

Adolescent; Adult; Child; Child, Preschool; Female; Humans; Male 